\title{
13. Significant economic impacts due to COVID-19 and falling remittances in Myanmar
}

\author{
Xinshen Diao and Michael Wang
}

The COVID-19 pandemic and government lockdown in Myanmar have led to falling exports and lost revenue from tourism and international remittances, hitting the economy hard. In a new series of policy notes, we examine the economic impacts of the pandemic and restrictive measures to mitigate the health crisis, and offer policy recommendations to address declining incomes and other impacts.

Our analysis shows a major short-term economic contraction as a result of the two-week lockdown in April - a 41\% decline in GDP along with similar declines in most nonagricultural sectors in comparison to the same period without a pandemic. This is not surprising, as Myanmar's economy is deeply integrated into a complex supply network both domestically and internationally, and policies affecting certain industries have ripple effects on other sectors through supply and demand linkages. In addition, approximately 4 million Myanmar migrants work internationally, and their lost income due to lockdowns in neighboring countries is expected to impose ongoing significant burdens on lowincome households that receive remittances.

In our analysis, we applied a social accounting matrix (SAM) multiplier model to evaluate COVID-19's direct and indirect effects on Myanmar's economy. The SAM multiplier model is a simulation tool that describes the economic connections between national economic actors and provides a highly disaggregated picture of the economy, which is suitable for measuring the impacts of short-term shocks.

The lockdown and subsequent restrictive measures have had direct and indirect negative impacts on the flow of goods and services, resulting in a decline of $41 \%$ in national GDP during the lockdown (Figure 1). The figure breaks down the decline further to show the different impacts of COVID-19 restrictions on Myanmar's various economic sectors.

We estimate that agricultural GDP fell 14\% during the two-week lockdown. While agricultural activities were mostly exempt from restrictions, the linkages with sectors in the rest of the economy led to significant indirect impacts, including reductions in demand from non-agricultural sectors, falling exports, lower consumer demand from falling remittance income, and difficulties in operating agribusinesses.

On their own, these negative short-term economic shocks are sufficiently large to temporarily push many Myanmar households into poverty and food insecurity. Moreover, our analysis shows that the sharp decline in remittance income is likely to continue for at least a year if not longer. As a result, many low-income households that sit just above the poverty line are expected to fall into poverty, and the extremity of poor households will increase (Figure 2). 
FIGURE 1 Estimated percentage change in Myanmar's GDP during the April 2020 two-week lockdown period by sector, compared with a normal situation without COVID-19 in the same period

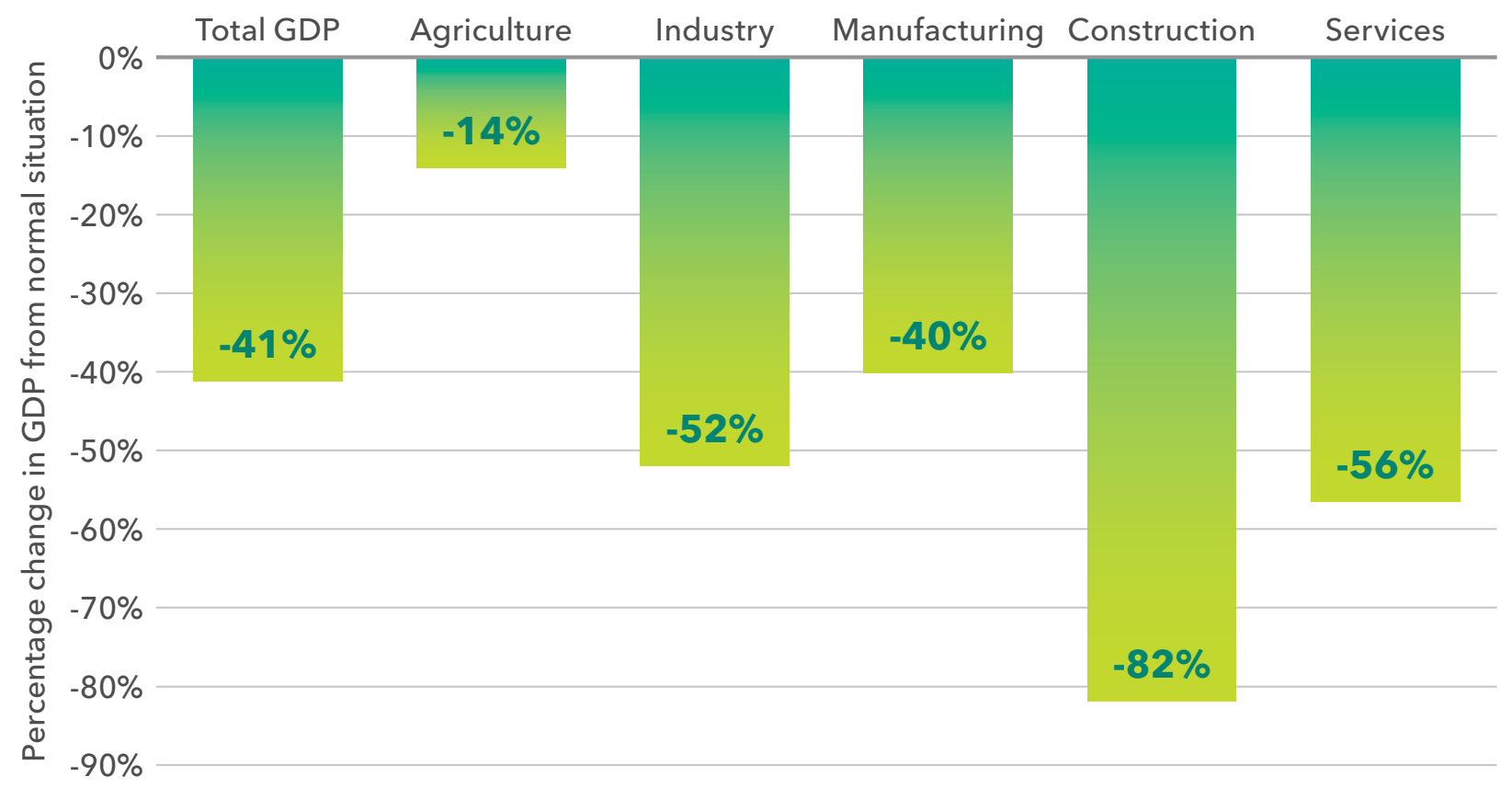

Source: IFPRI social accounting matrix (SAM) model.

FIGURE 2 Percent declines in total income due to a $50 \%$ international remittance shock and a 30\% domestic remittance shock among poor and low-income remittance-receiving households

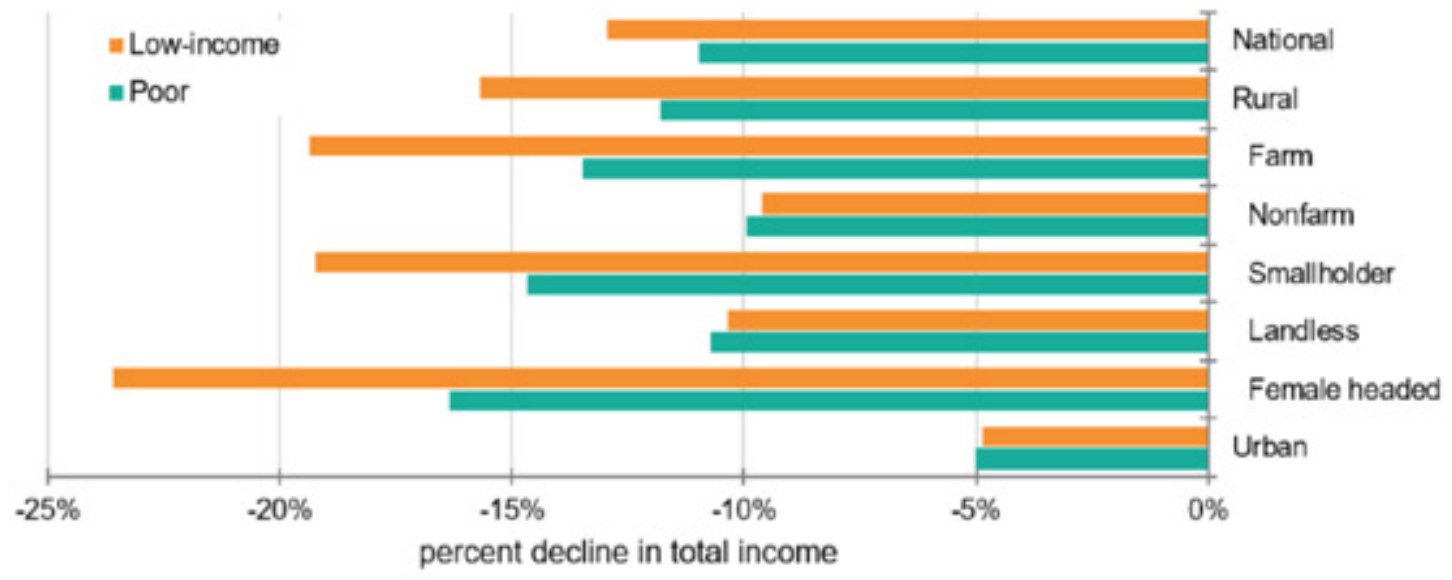

Source: SAM model.

Note: Farm, nonfarm, smallholder, landless, and female-headed households are part of rural households. Includes remittance-receiving households only. 
Declines in total income from remittance shocks are consistently higher among low-income rural households than poor rural households. However, though the shocks might result in smaller relative income losses for poor rural households, these households will see significant impacts because their income levels were initially much lower. Note that negative impacts on total income are largest for female-headed rural households.

The government recently released a comprehensive and sensible economic response package, the Myanmar COVID-19 Economic Relief Plan (CERP), which includes unconditional cash and in-kind transfers to the most vulnerable and affected households. The current analysis could be helpful in identifying potential recipients among remittance-receiving households and in determining the amount of financial support they need. The anticipated total spending under CERP will be around 2.8 trillion kyat (about US $\$ 2$ billion). Considering that the loss in national GDP estimated in our analysis is between 6.4 trillion and 9.0 trillion kyat by the end of FY 2020, the size of this economic stimulus package might be too modest to enable all firms, households, and the whole economy to return to their pre-COVID-19 growth trajectories in 2021.

Originally published June 25, 2020 